\title{
ALGORITHM 680 Evaluation of the Complex Error Function
}

\author{
G. P. M. POPPE and C. M. J. WIJERS \\ Twente University
}

Categories and Subject Descriptors: G.1.2 [Numerical Analysis]: Approximation-rational approximation; G.m [Mathematics of Computing]: Miscellanenus-FORTRAN

General Terms: Algorithm

Additional Key Words and Phrases: Error function of complex argument, recursive computation, Voigt function

\section{ALGORITHM}

Given a complex number $z$, in the first quadrant of the complex plane, $\operatorname{WOFZ}(z)$ computes the value of the Faddeeva-function $w(z)=\exp \left(-z^{2}\right) \cdot \operatorname{erfc}(-i z)$ with an accuracy of 14 significant digits. While the body of the algorithm is the same as that of Algorithm $363([1,2])$, the initialization part is largely changed so as to improve both the accuracy and the speed of the algorithm. The major distinction between Algorithm 363 and Algorithm 680 lies initially in the choice of the variable QRHO and in the fact that NU isn't a constant if (QRHO.GE.1.0), but decreases with increasing $|z|$. Secondly, in the neighborhood of the origin, a different approximation for the Faddeeva function is used. A full description of the differences between this algorithm and Algorithm 363 is given in [3].

\section{REFERENCES}

1. Gautschi, W. Efficient computation of the complex error function. SIAM J. Numer. Anal. 7, $187(1970)$.

2. GautschI, W. Algorithm 363-Complex error function. Commun. ACM 12, 635 (1969).

3. Poppe, G. P. M., AND WiJers, C. M. J. More efficient computation of the complex error function. This issue, pp. 38-46.

Received February 1988; revised January 1989; accepted March 1989

Authors' Address: Twente University, P.O. Box 217, 7500 AE Enschede, The Netherlands. Permission to copy without fee all or part of this material is granted provided that the copies are not made or distributed for direct commercial advantage, the ACM copyright notice and the title of the publication and its date appear, and notice is given that copying is by permission of the Association for Computing Machinery. To copy otherwise, or to republish, requires a fee and/or specific permission.

(C) 1990 ACM 0098-3500/90/0300-0047 $\$ 01.50$ 